\title{
Cervical Cancer Screening Practices and Barriers among Women in Nepal
}

\author{
Pravina Kafle ${ }^{1, *}$, Asha Panth ${ }^{2}$ \\ ${ }^{1}$ Department of Public Health, Pokhara University, Lekhnath municipality pokhara Nepal \\ ${ }^{2}$ Bheri Nursing College, Purbanchal University, Nepalgunj Banke Nepal \\ *Corresponding author: kaphlepraveena20@gmail.com
}

\begin{abstract}
Cervical cancer is cancer of the cervix which is caused by sexually-acquired infection with Human Papilloma Virus (HPV). Cervical cancer screening is the systematic application of Pap smear test to identify cervical abnormalities in an asymptomatic population. This paper tries to give an overview of cervical cancer screening practices and barriers in Nepal. During preparation of review paper various published Literature were obtained and reviewed from international journal and local newspaper and analyzed. In case of Nepal cervical cancer screening is still not giving high priority by women. Likewise Vaccine against HPV is not yet easily available in Nepal for early detection of cervical cancer due to lack of financial resources. High incidence of cervical cancer result due lack of awareness and knowledge, Pap test and HPV vaccine. Socio-cultural factors, low fund, less laboratory services, lack of privacy and informed consent pose barriers to have routine screening practices.
\end{abstract}

Keywords: burden, barriers, cervical cancer screening, Nepal, practices

Cite This Article: Pravina Kafl, and Asha Panth, "Cervical Cancer Screening Practices and Barriers among Women in Nepal.” American Journal of Cancer Prevention, vol. 5, no. 2 (2017): 31-33. doi: 10.12691/ajcp-5-2-4.

\section{Understanding of Cervical Cancer Screening}

Cervical cancer is cancer of the cervix where the organ that connects the uterus and the vagina. It is caused by sexually-acquired infection with Human papilloma virus (HPV). It is a serious medical problem and sometimes causes malignance and death [1] cervical cancer screening is the systematic application of Pap smear test to identify cervical abnormalities in an asymptomatic population. The Pap smear generally help to know women who do not have precancer. [2] Screening is recommended for every woman 30-49 years of age at least once in a life time. [3] According to estimation of International Agency for Research on Cancer (IARC) well-screened women aged 30-64 years, Pap smear screening prevented $80 \%$ of cervical cancer. [4] Center for disease control conclude that women should resume their regular cervical cancer screening test within their first sexual contact or with age of 21 years. [5]

\section{Methods}

During preparation of given article various published and literatures are taken and reviewed from international journals and local newspapers. Google scholar was also use to find various literatures by using keyword "Nepal", and "cervical cancer screening practices and barriers". All literatures were reviewed systematically and analyzed.

\section{Global Trend of Cervical Cancer}

Cervical cancer is one of the second most common cancers in women worldwide where more than 2,70,000 women die each year and more than $85 \%$ of these deaths are in low and middle income countries. [3] A highest incidence rate of cervical cancer-over 30 per 100,000 women was found in central and south America, SubSaharan Africa part of Oceana, the Caribbean, south and south East Asia. [6] About 5, 29, 800 new cases were estimated worldwide and of which more than $85 \%$ occurred in developing countries. Such burden of disease in developing countries is due to lack of screening. [7] The mortality rates are reported at 11.2 per 100,000 women on average in developing countries. [8] It was estimated that 53,000 women die of this disease each year in Africa where cervical cancer is a major health problem there. [9] Similarly India had reported to have higher incidence rate of cervical cancer about 30.7per 100,000 and mortality rate of 17.4 per 100,000 in South Central Asia. [10]

\section{Cervical Cancer Burden in Nepal: No of Cases and Mortality}

The gynecological, oncology unit at B.P koirala memorial hospital reveals that among all cancer cervical cancer is the commonest malignancies among women in Nepal. [11] The exact estimation of cancer is not well 
quoted in Nepal because of poor cancer registry system. However a retrospective study was developed by reviewing the medical records of the inpatient and outpatient department of B.P koirala memorial cancer hospital, from January 1999 to December 2008 (total of ten year period) Percentage of Cervical Cancer alone was found to be $29 \%$ which was in rising pattern. [12]

According to clinical data which was obtained from the department of pathology at BP Koirala Memorial cancer hospital over a period of 3 years (2009-2011) it was found that among total of 1955 register cases of gynecological malignancy the prevalence of cervical carcinoma was 1341(68\%). [13] Approximately 10.16 million Nepalese women ages 15 years and older are at risk of developing cervical cancer. According to information of Institute Cagtala D' Oncologia (ICO) crude incidence rate of cervical cancer is about $14.9 \%$ as well as annual number of new cases is about 2332 and mortality rate is 1367. [14]

Similarly clinical health camp held by the Nepal Fertility care Centerin Khokana of Lalitpur district where 73 married had pelvic screening including clinical diagnosis of cervicitis and vaginitis while cervicitis was detected in 16(23.5\%).This data concluded that many of the Nepalese married women are at the risk of having cervical carcinoma. [15] Previous study carried out in Department of Obstetrics/Gynecology and Pathology in Paropakar Maternity Women's Hospital from July 2013 to July 2015 among female shows that cervical cancer was found about $71 \%$ belong to $50-59$ years. [16] Nepal Fertility Care Center conducted health camp in Achham District of rural far western which was first study in Nepal to identify high risk HPV (HR-HPV) among rural women and found prevalence rate is $9.6 \%$. [17]

\section{Screening Practices}

Cervical cancer screening (Pap test) is still not giving high priority by Nepalese women as a result cervical cancer remains the most common cause of cancer-related mortality in women. [18] Nepal faces lots of problem for screening services due to limited medical services as well as geographical terrain which result difficulties for delivering health services. [19] Nepal Government has not approved Pap smear yet for the prevention of cervical cancer due to lack of advanced efficacy of test. The policy named as 'National guideline for cervical cancer screening and prevention in Nepal 2010' has 'Visual Inspection of cervix with Acetic Acid' which was found to be alternative screening in Nepal. [20]

According to Institute Cagtalad' Oncologia (ICO), Nepalese women are reported to have cervical cancer screening rate, is $2.8 \%$ in Nepal (14).Vaccine against HPV is not yet easily available in Nepal for early detection of cervical cancer due to lack of financial resources. [21]

One of the previous study shows that coverage of Pap smear test has been found to be $15.7 \%$ which is lower than global coverage. [22] Rarely Nepalese women undergo for cervical smear screening. The household survey was carried out in Nepal among 816 women of 21-65 years old and it was found that only 39 women had ever undergone smear test. [23]
Cancer treatment hospital and treatment facility are very few in Nepal only seven hospital provided cancer treatment services like B.P. Koirala Memorial Cancer Hospital, Bharatpur, Bir hospital/National Academy of Medical Sciences (NAMS), Kathmandu, Teaching Hopspital, Tribhuvan University, Kathmandu, Kanti Children's hospital, Kathmandu, Bhaktapur Cancer Hospital, Bhaktapur, Teaching Hospital, B. P. Koirala Memorial Institute of Health Sciences, Dharan, Teaching Hospital, Manipal College of Medical Sciences, Pokhara [24].

Recently pilot project in Nepal girls aged 9-13 years was vaccinate with human papillomavirus (HVP) to control cervical cancer in Chitwan and Kaski districts from this year, 2016 by Ministry of Health and Population which was formally inaugurated from kaski and HPV vaccine should be given twice at the interval of six months to complete the doses. In two districts (Kaski and Chitwan) about 15,000 girls immunized with HPV vaccine and the Ministry would extend the immunization programme in other remaining districts. [25]

Table 1. Age specific female population of Nepal eligible for cervical cancer

\begin{tabular}{|c|c|c|c|c|}
\hline AGE GROUP & $\mathbf{2 0 0 6}$ & $\mathbf{2 0 1 1}$ & $\mathbf{2 0 1 6}$ & $\mathbf{2 0 2 1}$ \\
\hline $30-34$ & 930,564 & $1,075,404$ & $1,223,906$ & $1,378,645$ \\
\hline $35-39$ & 777,905 & 915,024 & $1,059,865$ & $1,208,446$ \\
\hline $40-44$ & 643,984 & 761,034 & 897,527 & $1,041,809$ \\
\hline $45-49$ & 530,011 & 625,001 & 740,921 & 876,053 \\
\hline $50-54$ & 429,381 & 507,772 & 601,181 & 715,049 \\
\hline Total & $\mathbf{3 , 3 1 3 , 8 5 1}$ & $\mathbf{3 , 8 8 6 , 2 4 6}$ & $\mathbf{4 , 5 2 5 , 4 1 6}$ & $\mathbf{5 , 2 2 2 , 0 2 3}$ \\
\hline
\end{tabular}

Source: Central Bureau of Statistics (CBS)/UNFPA Population statistics of Nepal, 2004.

\section{Barriers in Timely Screening}

In developing country like Nepal high incidence of cervical cancer result due lack of awareness and knowledge about cervical cancer, pap test and HPV vaccine. [26] Similarly lack of perception about preventive role of Pap smear, lack of time and lack of permission from there husband to go to cervical cancer screening is also another determinants of barriers. [27] One study shows that lack of screening test is because of sensitive attitude of women toward screening like I feel awkward going to get Cervical cancer screening, Screening will be embarrassing to me, It take more time for screening and it may be painful. [28]

Likewise, Socio-cultural factors like ignorance, shyness to share problem with health worker, lack of income and beliefs on traditional healers are also pose barriers to early and routine screening. Low coverage of screening rate is often associated with less laboratory services and pathologists trained to evaluate cervical smears in rural parts of Nepal. [29]

Moreover, a strong barrier for less screening practices in case of Nepal is due to low fund arranged by government and lack of necessary resources. [28] In Nepal screening programs are often associated with ethical 
challenges. Meanwhile government had introduce commendable screening program and committed to reduce cervical cancer through it, but there are still issues and challenges to implement of cervical screening policy such as lack of discussion about various issues with respect to rights of clients on equal treatment, respecting their privacy, issues of informed consent, concerns about benefits and harms of screening and the right to appropriate treatment, which have not been sufficiently explored. [30]

\section{Conclusion}

In conclusion, cervical cancer screening practices and barriers revealed by the previous study provides vital information about the state of cervical cancer screening in Nepal. All above literatures facts supports that cervical cancer is the commonest malignancies among women in Nepal. The exact estimation of cancer is not well quoted in Nepal because of poor cancer registry system. A crude incidence rate of cervical cancer is about $14.9 \%$ as well as annual number of new cases is about 2332 and mortality rate is 1367. Nepal faces lots of problem for screening services due to limited medical services as well as geographical terrain which result difficulties for delivering health services. Vaccine against HPV is not yet easily available in Nepal for early detection of cervical cancer due to lack of financial resources. Socio-cultural factors, low fund, less laboratory services, lack of privacy and informed consent pose barriers to have routine screening practices. Special programs for screening of cervical cancer need to be designed and implement to women focusing on reducing burden of cervical cancer.

\section{References}

[1] Wikipedia. Cervical Cancer. Available from: https://simple.wikipedia.org/wiki/Cervical_cancer.

[2] Nanda K, McCrory DC, Myers ER, Bastian LA, Hasselblad V, Hickey JD, Matchar DB. Accuracy of the Papanicolaou test in screening for and follow-up of cervical cytologic abnormalities: a systematic review. Annals of internal medicine. 2000 May 16; 132(10): 810-9.

[3] World Health Organization. Comprehensive cervical cancer prevention and control: a healthier future for girls and women. Geneva, Switzerland: World Health Organization Press; 2013.

[4] Cervical Cancer prevention Fact Sheet. Risk Factors for Cervical Cancer: Evidence to date. Alliance for Cervical Cancer Prevention may 2004.

[5] Dixit S, Singh M. Cervical cancer in Nepali women. October 31, 2010.

[6] Ferlay J et al, editors. Globocan 2000: Cancer incidence, mortality and prevalence worldwide. IARC Cancer Base No. 5. Version 1.0.IARC Press, 2001.Lyon, France.

[7] Center M, Siegel R, Jemal A. Global cancer facts \& figures. Atlanta: American Cancer Society. 2011: 1-52.

[8] Ferlay J, Bray F, Pisani P, Parkin DM. Incidence rates are adjusted to account for differences in a gestructure across countries.

[9] Cervical Cancer: World Health Organization (WHO). Regional office for Africa; 2012
[10] Dabash R, Vajpayee J, Jacob M, Dzuba I, Lal N, Bradley J, Prasad LB. A strategic assessment of cervical cancer prevention and treatment services in 3 districts of Uttar Pradesh, India. Reproductive health. 2005 Dec 8; 2(1): 1.

[11] Annual Report, B.P. Koirala Memorial Cancer Hospital, Bharatpur Nepal; 2010.

[12] Jha AK, Jha J, Bista R, Basnet B, Kandel P, Lama G, Banthia P, Thakali K. A scenario of cervical carcinoma in a cancer hospital.Journal of Nepal Medical Association. 2009 Jul 1; 48(175).

[13] Pathak TB, Pun CB, Shrestha S, Bastola S, Bhatta R. Incidence, trends and histopathological pattern of cervical malignancies at BP Koirala Memorial cancer hospital, Nepal. Journal of Pathology of Nepal. 2013 Mar 27; 3(5): 386-9.

[14] “Institute Cagtalad' Oncologia” [ICO] Information Centreon HPV and Cancer. Human Papillomavirus and Related Cancers in Nepal, Fact Sheet. 2016 Available from: http://www.hpvcentre.net/statistics/reports/NPL_FS.pdf.

[15] Johnson D, Chamot E, Lhaki P, Broker TR, Steben M, Shrestha S. Prevalence and Correlates of Cervico-Vaginal Clinical Syndromes Among Women Attending a Health Camp in Lalitpur District of Nepal. Kathmandu University Medical Journal. 2015 Sep 23; 11(4): 268-73.

[16] JhaRJ,Baral G, Malla K.Malignat Tumor of the Female Genital Tract-Hospital Based Analysis.Nepali Journal of obstetrics and gynecology. 2015 Jul-Dec; 20 (2): 24-28.

[17] Johnson DC, Bhatta MP, Smith JS, Kempf MC, Broker TR, Vermund SH, Chamot E, Aryal S, Lhaki P, Shrestha S. Assessment of high-risk human papillomavirus infections using clinician-and self-collected cervical sampling methods in rural women from far western Nepal. PloS one. 2014 Jun 30; 9(6): e101255).

[18] Dr. Buddha Basnyat. Testing screens. The Nepali times. 2010. Available from:

http://nepalitimes.com/article/life-times/Testing-screens, 95.

[19] Joshi M, Mishra SR. Cervical Cancer Screening in Nepal. Health Prospect. 2013 Sep 24; 12(1): 18-20.

[20] Family Health Division (FHD).National Guideline for Cervical Cancer Screening and Prevention in Nepal; 2011.

[21] ICO, Human Papillomavirus and Related Cancers, Fact Sheet 2014 NEPAL. 2014).

[22] Ranabhat S, Tiwari M, Dhungana G, Shrestha R. Association of knowledge, attitude and demographic variables with cervical Pap smear practice in Nepal. Asian Pac J Cancer Prev. 2014 Jan 1; 15(20): 8905-10.

[23] Ranjit A, Gupta S, Shrestha R, Kushner AL, Nwomeh BC, Groen RS. Awareness and prevalence of cervical cancer screening among women in Nepal. International Journal of Gynecology \& Obstetrics. 2016 Mar 24.

[24] Pradhananga KK, Baral M, Shrestha BM. Multi-institution hospital-based cancer incidence data for Nepal: an initial report. Asian Pac J Cancer Prev. 2009 Jan 1; 10(2): 259-62.

[25] Sagun's Blog. HPV Vaccination program inaugurated from Pokhara, Kaski. 2016.

[26] Johnson DC, Bhatta MP, Gurung S, Aryal S, Lhaki P, Shrestha S. Knowledge and awareness of human papillomavirus (HPV), cervical cancer and HPV vaccine among women in two distinct Nepali communities. Asian Pac J Cancer Prev. 2014 Jan 1; 15: 8287-93.

[27] Sherpa AT. Time For An Organized Cervical Cancer Screening in Bharatpur, Nepal (Doctoral dissertation, University of Oslo).

[28] Satyal K. Cervical cancer screening behavior among Nepalese women (Doctoral dissertation, George Mason University).

[29] Sub-Saharienne A, y el Caribe AL, Asia S, Africa PS. Bringing science and development together through original news and analysis. Developing economies.; 221: 356.

[30] Gyawali B, Keeling JJ, van Teijlingen E, Dhakal L, Aro AR. cervical cancer screening in Nepal: ethical considerations. Medicolegal and Bioethics. 2015 Jan 16. 